\title{
Host-Guest Chemistry Meets Electrocatalysis: Cucurbit[6]uril on a Au Surface as a Hybrid System in $\mathrm{CO}_{2}$ Reduction
}

\author{
Andreas Wagner, ${ }^{\dagger, \bigcirc \odot ~ K h o a ~ H . ~ L y, ~}{ }^{\dagger, O,}$ Nina Heidary, ${ }^{\dagger, \pi}$ István Szabó, ${ }^{\S}$ Tamás Földes, ${ }^{\S}$ \\ Khaleel I. Assaf,,,$\square \odot$ Steven J. Barrow, ${ }^{\ddagger} \& \odot$ Kamil Sokołowski,,$\perp$ Mohamed Al-Hada, ${ }^{\ddagger} \odot$ \\ Nikolay Kornienko, ${ }^{\dagger, I \odot}$ Moritz F. Kuehnel, ${ }^{\dagger, \bullet}$ Edina Rosta, ${ }^{,} \odot$ Ingo Zebger, ${ }^{\nabla} \odot$ Werner M. Nau, ${ }^{\| \odot}$ \\ Oren A. Scherman, $* * \bullet$ and Erwin Reisner* ${ }^{*} \dagger \odot$
}

${ }^{\dagger}$ Christian Doppler Laboratory for Sustainable SynGas Chemistry, Department of Chemistry and ${ }^{\ddagger}$ Melville Laboratory for Polymer Synthesis, Department of Chemistry, University of Cambridge, Lensfield Road, Cambridge CB2 1EW, United Kingdom

${ }^{\S}$ Department of Chemistry, King's College London, 7 Trinity Street, SE1 1DB London, United Kingdom

"Department of Life Sciences and Chemistry, Jacobs University Bremen, Campus Ring 1, 28759 Bremen, Germany

${ }^{\perp}$ Institute of Physical Chemistry, Polish Academy of Sciences, Kasprzaka 44/52, 01-224 Warsaw, Poland

\#Cavendish Laboratory, Department of Physics, University of Cambridge, JJ Thomson Ave, Cambridge CB3 0HE, United Kingdom

${ }^{\nabla}$ Max Volmer Laboratorium für Biophysikalische Chemie, Sekr. PC14, Institut für Chemie, Technische Universität Berlin, Straße des 17. Juni 135, 10623 Berlin, Germany

\section{Supporting Information}

ABSTRACT: The rational control of forming and stabilizing reaction intermediates to guide specific reaction pathways remains to be a major challenge in electrocatalysis. In this work, we report a surface active-site engineering approach for modulating electrocatalytic $\mathrm{CO}_{2}$ reduction using the macrocycle cucurbit[6] uril ( $\mathrm{CB}[6])$. A pristine gold surface functionalized with $\mathrm{CB}[6]$ nanocavities was studied as a hybrid organic-inorganic model system that utilizes host-guest chemistry to influence the heterogeneous electrocatalytic reaction. The combination of surface-enhanced infrared absorption (SEIRA) spectroscopy and electrocatalytic experiments in conjunction with theoretical calculations supports capture and reduction of $\mathrm{CO}_{2}$ inside the hydrophobic cavity of $\mathrm{CB}[6]$ on the gold surface in aqueous $\mathrm{KHCO}_{3}$ at negative potentials. SEIRA spectroscopic experiments show that the decoration of gold with

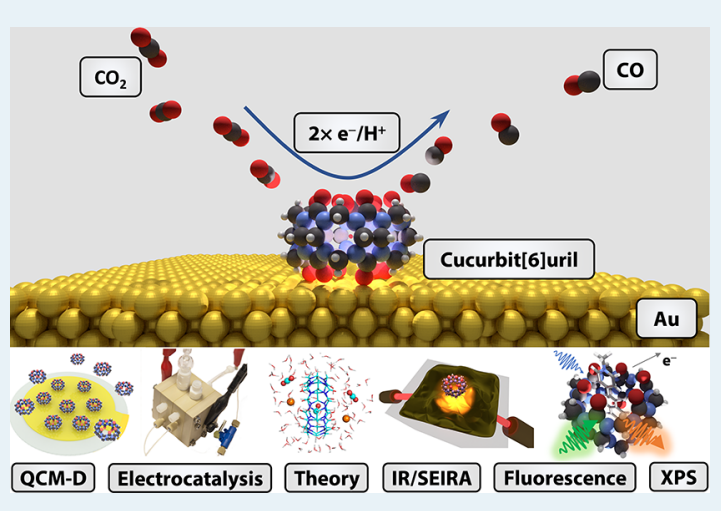
the supramolecular host $\mathrm{CB}[6]$ leads to an increased local $\mathrm{CO}_{2}$ concentration close to the metal interface. Electrocatalytic $\mathrm{CO}_{2}$ reduction on a $\mathrm{CB}[6]$-coated gold electrode indicates differences in the specific interactions between $\mathrm{CO}_{2}$ reduction intermediates within and outside the $\mathrm{CB}[6]$ molecular cavity, illustrated by a decrease in current density from $\mathrm{CO}$ generation, but almost invariant $\mathrm{H}_{2}$ production compared to unfunctionalized gold. The presented methodology and mechanistic insight can guide future design of molecularly engineered catalytic environments through interfacial host-guest chemistry.

KEYWORDS: surface active-site engineering, electrocatalytic $\mathrm{CO}_{2}$ reduction, host-guest chemistry, supramolecular catalysis

\section{INTRODUCTION}

The electrocatalytic reduction of $\mathrm{CO}_{2}$ using renewable energy sources offers an attractive route to produce storable carbonneutral fuels. ${ }^{1,2}$ For this technology to become commercially viable, catalysts that promote the challenging multi-electron/proton transfer reaction with minimal energy losses and high rate and selectivity need to be developed. Currently, $\mathrm{CO}_{2}$ reduction suffers from significant overpotentials, sluggish kinetics, and low selectivity control as well as the low solubility of $\mathrm{CO}_{2}$ in aqueous electrolytes. ${ }^{3-5}$ Gold $(\mathrm{Au})$ is generally considered the most active electrocatalyst for $\mathrm{CO}$ generation with a catalytic onset potential ca. $300 \mathrm{mV}$ more negative than the standard potential for $\mathrm{CO}_{2}$ to $\mathrm{CO}$ reduction on flat electrodes. $^{6-8}$ The catalytic mechanism on $\mathrm{Au}$ is believed to involve a surface-bound $\mathrm{COOH}(* \mathrm{COOH})$ intermediate, which is subsequently further reduced by $1 \mathrm{e}^{-} / 1 \mathrm{H}^{+}$transfer to yield $\mathrm{CO}(* \mathrm{CO})$ that is finally liberated from the surface. Theoretical predictions indicate that stronger binding of the $* \mathrm{COOH}$ intermediate relative to ${ }^{*} \mathrm{CO}$ may be needed for enhanced $\mathrm{CO}$ evolution activity. ${ }^{9,10}$ However, the binding energies of $* \mathrm{COOH}$ and $* \mathrm{CO}$ on electrocatalysts generally correlate; ${ }^{11}$ therefore, stabilization of ${ }^{*} \mathrm{COOH}$ would simultaneously stabilize $* \mathrm{CO}$ and thus disfavor its required desorption. This scaling relationship impedes a straightforward

Received: September 30, 2019

Revised: November 18, 2019

Published: November 20, 2019 
approach to independently fine-tune surface properties for higher activities, hampering the development of low overpotential single-site metal catalysts. ${ }^{12}$

To this end, different approaches such as alloying, ${ }^{13,14}$ nanostructuring, ${ }^{15}$ and molecular surface modification ${ }^{16-20}$ have recently gained attention. Nevertheless, molecular engineering of an electrocatalytic surface site remains to be challenging. Nature, on the other hand, has developed very effective catalytic systems that surpass the limits of scaling relationships. Enzymes such as carbon monoxide dehydrogenase and formate dehydrogenase are able to reversibly interconvert $\mathrm{CO}_{2}$ at the thermodynamic potential with quantitative product selectivity at their precious-metal free active sites. ${ }^{21-23}$ While details about their reaction mechanisms are still under debate, a hydrophobic active site cavity and the stabilization of intermediates by a highly specific second coordination sphere are believed to be crucial for their high activity as well as selectivity. ${ }^{9,24,25}$

In our efforts to create analogous synthetic reaction environments, we envision supramolecular host-guest chemistry as a powerful tool to modulate electrocatalytic reactions by selectively favoring certain species due to highly specific binding affinities. Cucurbit $[n]$ urils $(\mathrm{CB}[n]$ where $n=5-8)$ are a class of promising host molecules for this purpose. These barrel-shaped organic macrocycles are water-soluble and have found broad applications in materials chemistry, drug delivery systems, sensing, and catalysis (Figure $1 \mathrm{a}) .{ }^{26,27} \mathrm{CB}[n] \mathrm{s}$ are able to shift the reduction potential of electrochemical processes by selectively stabilizing certain species. ${ }^{28,29}$ For example, halfwave potentials of ferrocene and methyl viologen can be positively shifted upon complexation with $\mathrm{CB}[7]$ due to different stabilization of the oxidized versus reduced species within the cavity.

The cavities of $\mathrm{CB}[n]$ are highly hydrophobic ${ }^{30}$ and bind a plethora of small organic guests (for $n \geq 6$ ) as well as gas molecules (for $n \leq 6) .{ }^{26}$ In aqueous solutions, a large number of gases (e.g., $\mathrm{CH}_{4}$, acetylene, and cyclopentane) form inclusion complexes within $\mathrm{CB}[6] .^{31}$ Their negatively polarized carbonyl-lined portals exhibit high affinity toward metal surfaces allowing for facile supramolecular functionalization of electrodes. $^{32}$ In contrast, other hosts such as pillararenes, cyclodextrins, and calixarenes typically rely on additional steps for electrode immobilization, which often afford increased distances between the host cavity and the surface. ${ }^{33-35}$ Their ability to directly affect surface-bound species is thereby diminished.

It has been shown spectroscopically and by gravimetric measurements that $\mathrm{CB}[6]$ can be used as a highly porous solidstate adsorbent for gaseous $\mathrm{CO}_{2}$ with high selectivity over $\mathrm{CO}$,
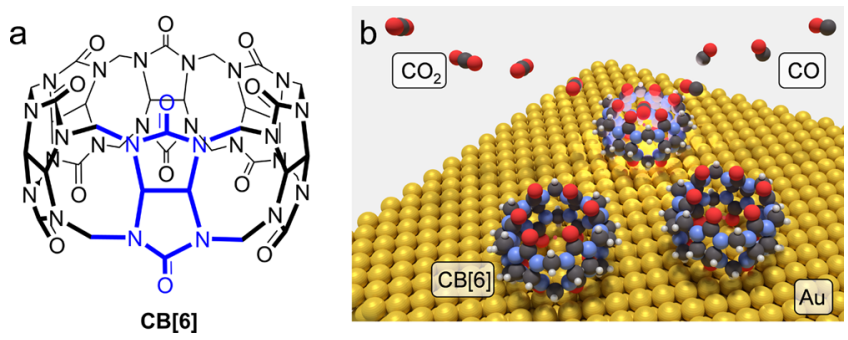

Figure 1. (a) $\mathrm{CB}[6]$ structure with monomeric building block highlighted in blue. (b) Schematic illustration of $\mathrm{CO}_{2}$ conversion to $\mathrm{CO}$ within the cavity of $\mathrm{CB}[6]$ adsorbed on a $\mathrm{Au}$ surface. rendering this molecule to be attractive for combining hostguest chemistry and electrocatalytic $\mathrm{CO}_{2}$ reduction studies. ${ }^{36,37}$ To the best of our knowledge, neither has $\mathrm{CO}_{2}$ complexation within $\mathrm{CB}[6]$ in solution been demonstrated nor has $\mathrm{CB}[6]$ been used in electrocatalytic $\mathrm{CO}_{2}$ reduction.

In this work, we study $\mathrm{CB}[6]$ as a prototypical synthetic organic cavity system for facile manipulation of the heterogeneous $\mathrm{CO}_{2}$ reduction on $\mathrm{Au}$, a well-studied model electrocatalyst (Figure 1b). First, the host-guest interaction of $\mathrm{CO}_{2}$ with $\mathrm{CB}[6]$ is studied in homogeneous aqueous solution both experimentally and computationally. Subsequently, we employ surface-enhanced infrared absorption (SEIRA) spectroscopy combined with electrochemistry to investigate the behavior of $\mathrm{CO}_{2}$ within $\mathrm{CB}[6]$ on the $\mathrm{Au}$ surface during electrocatalysis.

\section{RESULTS AND DISCUSSION}

Interaction of $\mathrm{CO}_{2}$ with $\mathrm{CB}[6]$ in Solution. The inclusion of $\mathrm{CO}_{2}$ in $\mathrm{CB}[6]$ was monitored in aqueous $\mathrm{KHCO}_{3}(0.1 \mathrm{M})$ using Fourier-transform infrared (FTIR) spectroscopy in transmission mode (Figure 2a). The asymmetric stretching mode of ${ }^{12} \mathrm{CO}_{2}$ was found at 2343 $\mathrm{cm}^{-1}$, which is in line with previously reported values for ${ }^{12} \mathrm{CO}_{2}$ in solution. ${ }^{38}$ In the presence of $8.44 \mathrm{mM} \mathrm{CB}[6]$, an additional shoulder was detected at $2333 \mathrm{~cm}^{-1}$. This band was exclusively observed in a ${ }^{12} \mathrm{CO}_{2}$-purged electrolyte solution (Figure $\mathrm{S} 1$ ) and therefore assigned to an interaction between $\mathrm{CO}_{2}$ and $\mathrm{CB}[6]\left(\mathrm{CB}[6] \cdot \mathrm{CO}_{2}\right)$. The corresponding ${ }^{13} \mathrm{CO}_{2}$ asymmetric stretching vibration ${ }^{38}$ identified at $2278 \mathrm{~cm}^{-1}$ displayed an identical shift by $10 \mathrm{~cm}^{-1}$ to $2268 \mathrm{~cm}^{-1}$, confirming this band to originate from $\mathrm{CO}_{2}$.

The observed shift matches the previously reported values for the asymmetric stretching mode of $\mathrm{CO}_{2}$ confined in solid $\mathrm{CB}[6]$ at $2336 \mathrm{~cm}^{-1} \cdot{ }^{36,37}$ Addition of spermine, a well-known $\mathrm{CB}[6]$ guest with a high binding affinity, ${ }^{26}$ led to disappearance of the band at $2333 \mathrm{~cm}^{-1}$, which is in line with a competitive displacement of $\mathrm{CO}_{2}$ from the cavity. Moreover, the IR signature of the $\mathrm{CB}[6]$ framework remained unchanged in the presence of $\mathrm{N}_{2}$ and ${ }^{12} \mathrm{CO}_{2} /{ }^{13} \mathrm{CO}_{2}$, indicating that the $\mathrm{CB}[6] \cdot \mathrm{CO}_{2}$ (binding) interaction is weak and nondirectional (Figure 2b). In contrast, spermine addition gave rise to a strong additional band at $1727 \mathrm{~cm}^{-1}$. This band can be rationalized by a shift of the carbonyl stretching mode from $1743 \mathrm{~cm}^{-1}$ by $16 \mathrm{~cm}^{-1}$ as a result of electrostatic interactions with the positively charged amine functional group of spermine. ${ }^{39}$ Analogously, the unaltered $\mathrm{CB}[6]$ carbonyl band in the presence of $\mathrm{CO}_{2}$, when compared to the $\mathrm{CB}[6]$-spermine host-guest complex, suggests that $\mathrm{CO}_{2}$ is not merely associated with the carbonyl portal region of $\mathrm{CB}[6]$. In conclusion, the IR data strongly suggests that $\mathrm{CO}_{2}$ is bound inside the $\mathrm{CB}[6]$ cavity in solution with an IR marker band located at $2333 \mathrm{~cm}^{-1}$. We note that the binding of $\mathrm{CO}$ to $\mathrm{CB}[6]$ could not be probed due to its low solubility in the reaction solution.

The assignment of the $\mathrm{CO}_{2}$ interaction with $\mathrm{CB}[6]$ is further corroborated by density functional theory (DFT) and molecular dynamics (MD) simulations (Table S1 and Figures $\mathrm{S} 2-\mathrm{S} 5$ ). Both methods show a stronger binding of $\mathrm{CO}_{2}$ over $\mathrm{CO}$ in $\mathrm{CB}[6]$, which is in line with previously reported DFT results. ${ }^{40} \mathrm{~A}$ free-energy profile based on umbrella sampling of $\mathrm{MD}$ simulations of $\mathrm{CO}_{2}$ and $\mathrm{CO}$ is shown in Figure $3 \mathrm{a}$. The results suggest that $\mathrm{CO}_{2}$ and $\mathrm{CO}$ need to overcome a low energy barrier when entering the cavity and reach an energy 

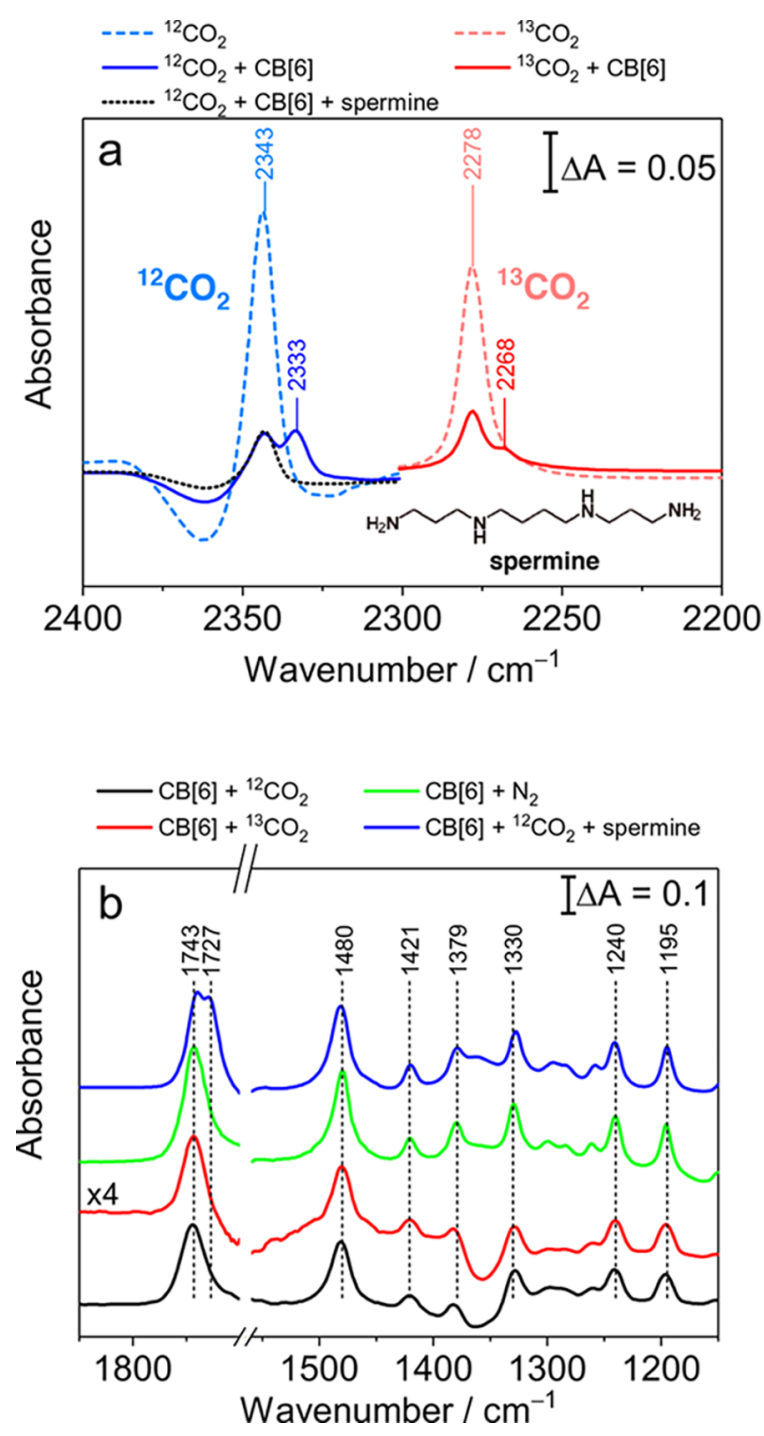

Figure 2. FTIR spectra of $\mathrm{CB}[6]$ solutions recorded in the transmission mode. (a) Absorbance spectra of asymmetric stretching modes of ${ }^{12} \mathrm{CO}_{2}$ in aqueous $\mathrm{KH}^{12} \mathrm{CO}_{3}(0.1 \mathrm{M})$ and ${ }^{13} \mathrm{CO}_{2}$ in $\mathrm{NaH}^{13} \mathrm{CO}_{3}(0.1 \mathrm{M})$ solution. The reference spectra for dashed spectra were the $\mathrm{N}_{2}$ purged electrolytes. Spectra of $\mathrm{CB}[6]$ from which the CB-free $\mathrm{CO}_{2}$ reference spectrum was subtracted display a shoulder at 2333 and $2268 \mathrm{~cm}^{-1}$. The addition of spermine (strong $\mathrm{CB}[6]$ cavity binder) leads to disappearance of the $2333 \mathrm{~cm}^{-1}$ band. The broad negative band at ca. $2360 \mathrm{~cm}^{-1}$ results from small atmospheric $\mathrm{CO}_{2}$ variations between measurements. (b) IR spectra of the region below $1800 \mathrm{~cm}^{-1}$ representing the vibrational modes for $\mathrm{CB}[6]$ in ${ }^{12} \mathrm{CO}_{2}$ purged $0.1 \mathrm{M} \mathrm{KH}^{12} \mathrm{CO}_{3}$ and ${ }^{13} \mathrm{CO}_{2}$-purged $0.1 \mathrm{M} \mathrm{NaH}^{13} \mathrm{CO}_{3}$, which exhibit no band shifts in comparison to the $\mathrm{N}_{2}$-purged $0.1 \mathrm{M}$ $\mathrm{KH}^{12} \mathrm{CO}_{3}$ solution. Addition of spermine leads to an additional band at $1727 \mathrm{~cm}^{-1}$ assigned to carbonyl functional groups of $\mathrm{CB}[6]$, presumably occurring due to the interaction of the spermine nitrogen and $\mathrm{CB}[6]$ carbonyl ring. The spectrum of the $\mathrm{CB}[6]{ }^{13} \mathrm{CO}_{2}$-purged sample was multiplied by a factor of 4 for better comparison (see experimental details in the Supporting Information).

minimum at the cavity center. $\mathrm{CO}_{2}$ was found to bind with two possible conformations in the pocket (second local minima found at $z= \pm 3.1 \AA$ ). A snapshot of the final state after $22 \mathrm{~ns}$ of a MD simulation in $\mathrm{KHCO}_{3}(0.1 \mathrm{M})$ is shown in Figure $3 \mathrm{~b}$. The CO molecule was initially placed in the cavity center and was found to be eventually replaced by two $\mathrm{CO}_{2}$ molecules at the given concentration. The free-energy profiles were used to
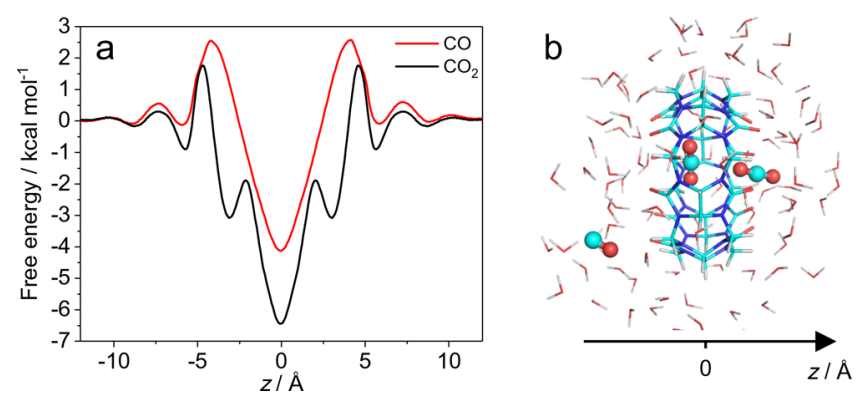

Figure 3. $\mathrm{CO}_{2}$ and $\mathrm{CO}$ inclusion in $\mathrm{CB}[6]$ in $0.1 \mathrm{M} \mathrm{KHCO}_{3}$ studied by $\mathrm{MD}$ simulations. (a) Free-energy profile of $\mathrm{CO}_{2}$ and $\mathrm{CO}$ passing through the cavity of $\mathrm{CB}[6]$ along a central axis (the $z$ axis is illustrated in (b) based on umbrella sampling of MD simulations). (b) Snapshot of MD simulation with one "deep cavity"-bound $\mathrm{CO}_{2}$, one $\mathrm{CO}_{2}$ loosely associated with carbonyl ring, and one unbound $\mathrm{CO}$.

calculate the binding constants $K_{\mathrm{a}, \mathrm{CO} 2}=105 \mathrm{M}^{-1}$ and $K_{\mathrm{a}, \mathrm{CO}}=5$ $\mathrm{M}^{-1}$ for $\mathrm{CB}[6] \cdot \mathrm{CO}_{2}$ and $\mathrm{CB}[6] \cdot \mathrm{CO}$, respectively (binding free-energies of 6.4 and $4.1 \mathrm{kcal} \mathrm{mol}^{-1}$, respectively, see the Supporting Information for computational details).

To quantify the binding of $\mathrm{CO}_{2}$ and $\mathrm{CB}[6]$ experimentally, fluorescent dye displacement measurements were performed (Figure $4 \mathrm{a}$ and Figure S6). This technique utilizes the fluorescence of the host-guest complex of $\mathrm{CB}[6]$ with an indicator dye, in this case trans-4[4-(dimethylamino)styryl]-1methylpyridinium (DSMI, inset of Figure 4a). DSMI is weakly fluorescent on its own but strongly fluorescent in the complexed state. ${ }^{41}$ The competitive binding of $\mathrm{CO}_{2}$ and DSMI to the $\mathrm{CB}[6]$ cavity (Figure $4 \mathrm{~b}$ ) was used to determine a binding constant $\left(K_{\mathrm{a}, \mathrm{CO} 2}\right)$ of $250 \pm 100 \mathrm{M}^{-1}$ in $0.1 \mathrm{M}$ $\mathrm{KHCO}_{3}$ for the $\mathrm{CB}[6] \cdot \mathrm{CO}_{2}$ host-guest complex. The experimental finding was qualitatively confirmed with a second indicator dye (Figure S6). This sizable affinity is in good agreement with the computational data. Unfortunately, CO afforded only a small change in fluorescence owing to its low solubility, which prevented an accurate quantification of its binding constant. However, well-established trends of gas affinities and corresponding volume/packing coefficients ${ }^{31}$ along with the performed DFT and MD calculations suggest a weaker binding of $\mathrm{CO}$ than that of $\mathrm{CO}_{2}$ to $\mathrm{CB}[6]$. These findings indicate that there is no product inhibition (i.e., $\mathrm{CO}$ occupying the $\mathrm{CB}[6]$ pocket due to a higher binding affinity than that of $\mathrm{CO}_{2}$ ), which is a general concern in (supramolecular) catalysis. ${ }^{42}$

Au Electrode Modification with $\mathrm{CB}[6]$. The binding of $\mathrm{CB}[6]$ to $\mathrm{Au}$ surfaces has previously been reported ${ }^{32,43}$ but rarely quantitatively. The effect of the solvent and the nature and concentration of the electrolyte were suspected to have a large effect on the surface adsorption equilibrium. Solubility of $\mathrm{CB}[6]$ in water is typically very low $(<100 \mu \mathrm{M}),{ }^{44}$ but it can be readily increased by more than 2 orders of magnitude through addition of cationic species to the solution. ${ }^{45}$ Besides the increased solubility, the interaction of cations with $\mathrm{CB}[6]$ influences the kinetics of host-guest complex formation. ${ }^{46}$ As an additional complexity, cations themselves have shown to effect $\mathrm{CO}_{2}$ reduction on heterogeneous electrocatalysts. ${ }^{4-50}$ Considering these multiple intricate effects of cations in the system, we employed an aqueous $\mathrm{KHCO}_{3}(0.1 \mathrm{M})$ electrolyte solution, which is also commonly used in $\mathrm{CO}_{2}$ reduction catalysis. ${ }^{51,52}$ This concentration fulfills the necessity for supporting electrolytes during electrocatalytic $\mathrm{CO}_{2}$ reduction and overcomes the limited solubility of $\mathrm{CB}[6]$ while 

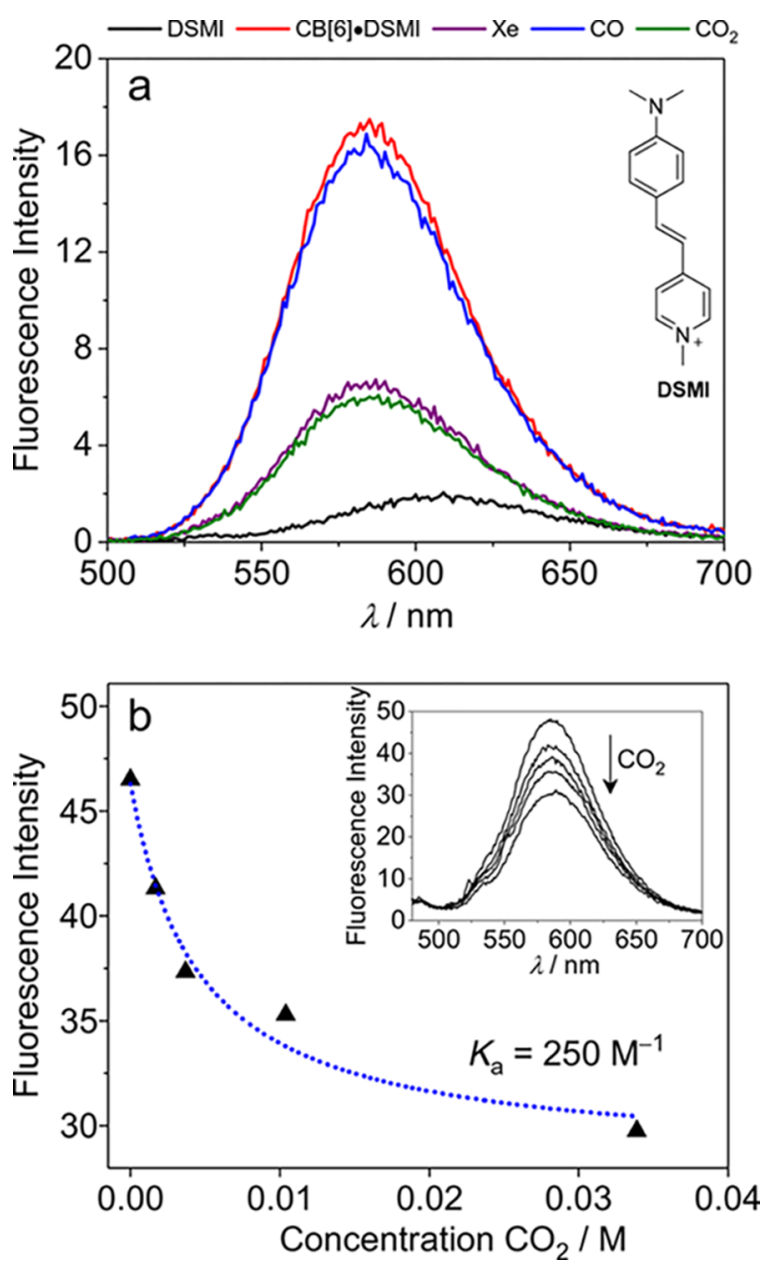

Figure 4. Fluorescent dye displacement measurements. (a) Fluorescence intensity of CB-free DSMI and the CB[6].DSMI complex with and without competitive guests. The solution was saturated with the respective gas. Xe was used as a control with a known binding affinity. The DSMI counterion (iodide) was removed for clarity. (b) Decrease in fluorescence intensity of the CB[6].DSMI complex with increasing $\mathrm{CO}_{2}$ concentration to calculate the binding affinity of $\mathrm{CO}_{2} \cdot \mathrm{CB}[6]$ based on the known binding affinity of DSMI. The concentration of $\mathrm{CO}_{2}$ was determined via Henry's law (see the Supporting Information for details). Experimental conditions: $0.1 \mathrm{M}$ $\mathrm{KHCO}_{3}$, [dye $]=1 \mu \mathrm{M},[\mathrm{CB}[6]]=50 \mu \mathrm{M}$, excitation wavelength $=$ $283 \mathrm{~nm}$, and $K_{\mathrm{a}, \mathrm{DSMI}}$ determined as $2100 \mathrm{M}^{-1}$ in $0.1 \mathrm{M} \mathrm{KHCO}_{3}$ (Figure S6).

minimizing the effects of cations on the host-guest complexation as well as on $\mathrm{CO}_{2}$ reduction to a minimum.

The adsorption of $\mathrm{CB}[6]$ on $\mathrm{Au}$ was first quantified by quartz-crystal microbalance (QCM) measurements at opencircuit potential in $\mathrm{N}_{2}$-purged $\mathrm{KHCO}_{3}$ as shown in Figure 5a. The coverage was estimated using the Sauerbrey model, ${ }^{53}$ assuming a flat gold surface and a van der Waals radius of "rigid" $\mathrm{CB}[6]$ of $14.4 \AA \AA^{45}$ A theoretical monolayer coverage of ca. $80 \pm 20 \%$ for $1.69 \mathrm{mM} \mathrm{CB}[6]$ was determined with a Langmuir isotherm. Considering the highest density of hexagonally packed circles within a plane (ca. 90\%), the data obtained from QCM is close to that for an optimally covered surface.

QCM was not only applied to study surface adsorption processes by mass changes but also further utilized to obtain insights into the viscoelasticity of the adsorbed layer by studying its dissipation behavior. ${ }^{54}$ This can be particularly
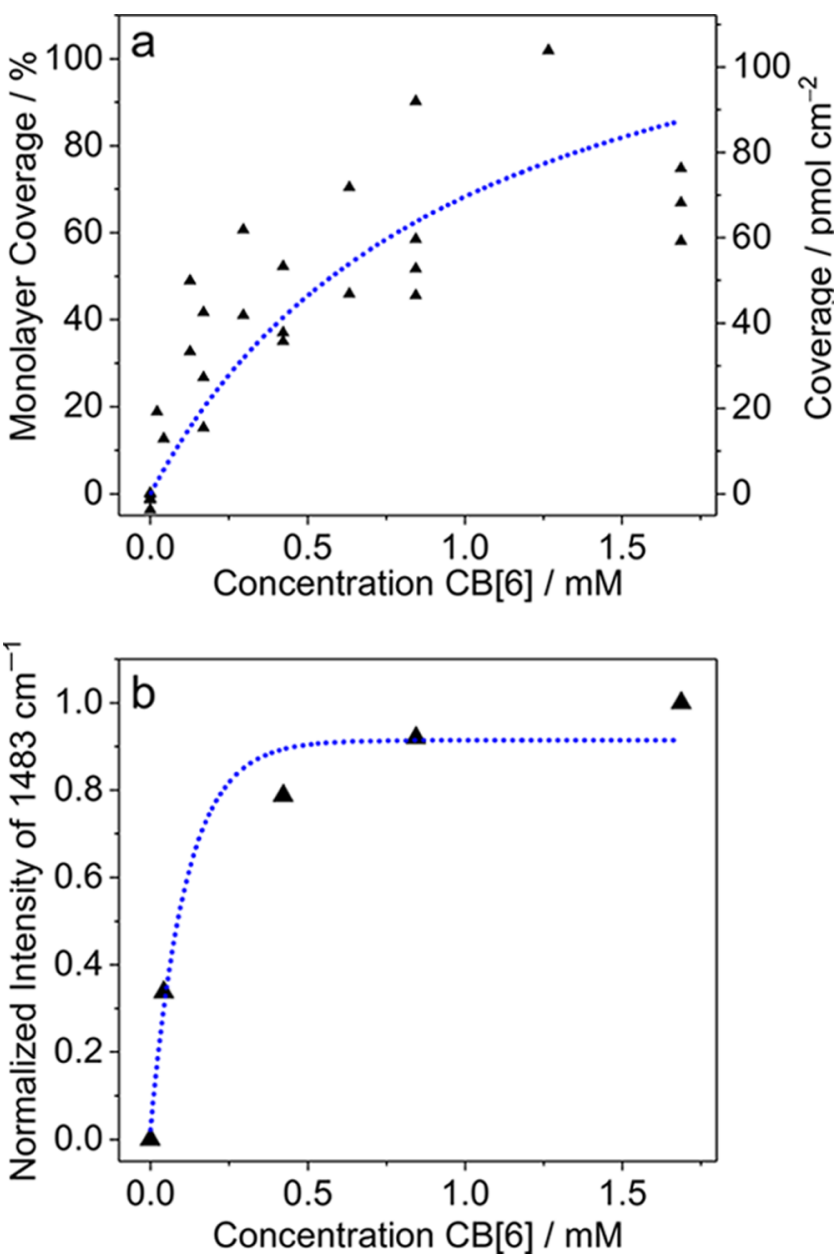

Figure 5. Surface adsorption of $\mathrm{CB}[6]$ on $\mathrm{Au}$. (a) Monolayer coverage of $\mathrm{CB}[6]$ on Au-based on quartz-crystal microbalance measurements at an open-circuit potential. The data was modeled with the Sauerbrey equation and fitted with a Langmuir isotherm (blue dashed line). (b) Increase in relative intensity of the $\mathrm{CB}[6]$ band at $1483 \mathrm{~cm}^{-1}$ in SEIRA measurements and an exponential fit to guide the eye (blue dashed line).

useful to gather information on changes of layer packing or, importantly, multilayer formation. ${ }^{55,56}$ Measurements indicated that, for concentrations of $>0.8 \mathrm{mM}$, the dissipation starts to increase, suggesting the formation of multilayers of $\mathrm{CB}[6]$ (Figure S7). Multilayer buildup of $\mathrm{CB}[6]$ on surfaces has been observed previously for $\mathrm{CB}[6]$ in solutions containing $\mathrm{Na}^{+} .57$ Furthermore, formation of chain-like coordination polymers between $\mathrm{CB}[6]$ and $\mathrm{K}^{+}$has been reported in the solid state. ${ }^{58,59}$

The interaction of $\mathrm{CB}[6]$ with the Au surface was further probed by SEIRA spectroscopy, which selectively monitors the $\mathrm{Au}$-electrolyte interface (see below). ${ }^{60,61}$ The vibrational band pattern of $\mathrm{CB}[6]$ revealed significantly different relative intensities between SEIRA and transmission measurements due to surface selection rules, indicating a preferential binding geometry of $\mathrm{CB}[6]$ on the surface compared to the isotropic case in solution (Figure S8). A notable shift of the carbonyl stretching mode from $1743 \mathrm{~cm}^{-1}$ in solution to $1737 \mathrm{~cm}^{-1}$ on the $\mathrm{Au}$ surface further suggests an interaction between (one of) the carbonyl-lined portals of $\mathrm{CB}[6]$ with the gold surface, which is in line with previous reports. ${ }^{32,43,62}$ Figure 5 b shows the normalized intensity of the intense $1483 \mathrm{~cm}^{-1}$ marker band 

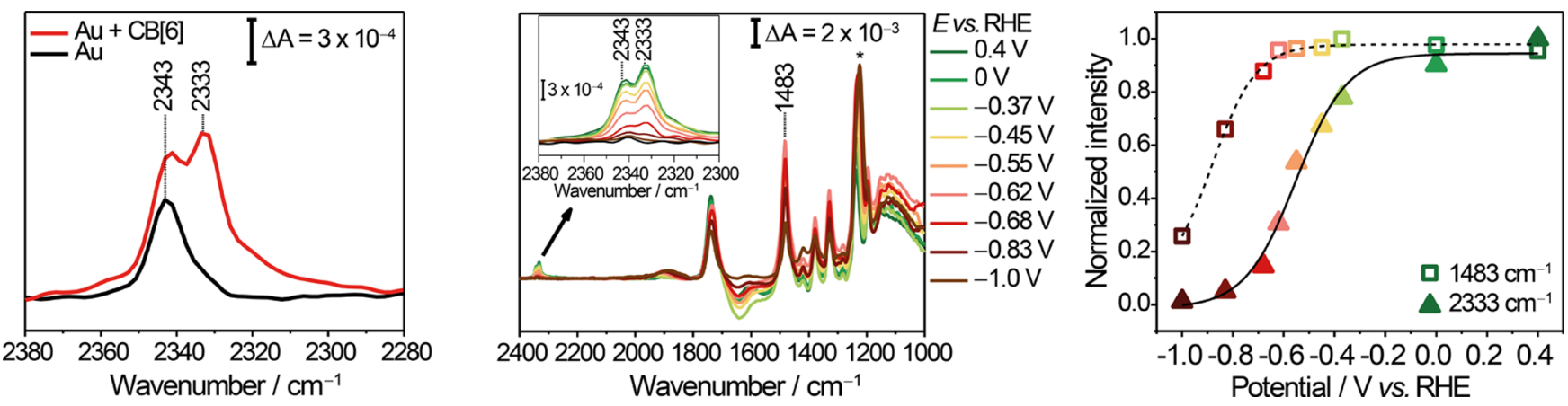

Figure 6. SEIRA measurements of $\mathrm{CB}[6] \cdot \mathrm{CO}_{2}$ on Au. (a) SEIRA spectra of $\mathrm{CO}_{2}$-purged $0.1 \mathrm{M} \mathrm{KHCO}_{3}$ (black) and $1.69 \mathrm{mM} \mathrm{CB}[6]$ in $0.1 \mathrm{M}$ $\mathrm{KHCO}_{3}$ (red). Reference spectra: unmodified Au in argon-purged $0.1 \mathrm{M} \mathrm{KHCO}_{3}$. (b) Potential dependent SEIRA spectra showing stepwise desorption of $\mathrm{CB}[6]$ from the surface at potentials more negative than $-0.7 \mathrm{~V}$ vs RHE. Inset: the $\mathrm{CB}[6] \cdot \mathrm{CO}_{2}$ band at $2333 \mathrm{~cm}^{-1}$ decreases rapidly at $\mathrm{CO}_{2}$ reduction turnover potentials. Reference spectra: unmodified $\mathrm{Au}$ in argon-purged $0.1 \mathrm{M} \mathrm{KHCO}_{3}$ at respective potentials. A spectral artifact (due to $\mathrm{SiO}_{2}$ from the prism) at $1239 \mathrm{~cm}^{-1}$ marked with a star was found to have increased. (c) Normalized (between maximum and 0 ) intensity decline of band at 2333 and $1483 \mathrm{~cm}^{-1}$ with sigmoidal fits. Conditions: $1.69 \mathrm{mM} \mathrm{CB}[6]$ in $0.1 \mathrm{M} \mathrm{KHCO}_{3}$. All potentials were $i R$-corrected (see the Supporting Information for details).

of $\mathrm{CB}[6]$ as a function of the $\mathrm{CB}[6]$ concentration in solution. No notable increase was observed for concentrations higher than ca. $1.3 \mathrm{mM}$ (Figure S9), matching the concentration at which multilayer formation was observed in QCM measurements (Figure S7). As the SEIRA intensity $I$ decreases significantly with distance $d$ from the electrode surface $(I \approx$ $\left.d^{-6}\right)$, potential multilayers of $\mathrm{CB}[6]$ cannot be monitored. ${ }^{63}$ SEIRA as well as X-ray photoelectron spectroscopy (XPS) indicated a stable surface-bound $\mathrm{CB}[6]$ layer after overnight soaking in a $\mathrm{CB}[6]$-free $0.1 \mathrm{M} \mathrm{KHCO}_{3}$ aqueous electrolyte solution (Figures S10 and S11).

SEIRA Measurements of $\mathrm{CB}[6] \cdot \mathrm{CO}_{2}$ under Polarization. SEIRA spectroscopy has recently gained increased attention in the field of $\mathrm{CO}_{2}$ reduction catalysis due to its high sensitivity for surface processes. ${ }^{64-67}$ Typically, the strong IR activity of $\mathrm{CO}$ and $\mathrm{HCO}_{3}^{-} / \mathrm{CO}_{3}{ }^{2-}$ is exploited to track specific bands to monitor product stability and binding, the bicarbonate $/ \mathrm{CO}_{2}$ equilibrium, and the role of cations. In this study, we specifically focus on the role of $\mathrm{CO}_{2}$ and its fate upon inclusion into $\mathrm{CB}[6]$ during electrocatalytic turnover (see Figure 6).

Upon purging the electrolyte solution containing $1.69 \mathrm{mM}$ $\mathrm{CB}[6]$ with $\mathrm{CO}_{2}$, the band at $2333 \mathrm{~cm}^{-1}$ assigned to $\mathrm{CB}[6] \cdot \mathrm{CO}_{2}$ appeared, indicating that $\mathrm{CO}_{2}$ can efficiently penetrate the $\mathrm{CB}[6]$ cavity when the host molecule is bound to the Au surface. Compared to the isotropic case in the solution, the $\mathrm{CB}[6] \cdot \mathrm{CO}_{2}$ band showed an increased intensity in the SEIRA spectra (Figure 6a) relative to the unaltered $\mathrm{CO}_{2(\mathrm{aq})}$ band at $2343 \mathrm{~cm}^{-1}$, suggesting an increase in the total $\mathrm{CO}_{2}$ concentration (i.e., free $\mathrm{CO}_{2(\mathrm{aq})}$ and $\mathrm{CB}[6] \cdot \mathrm{CO}_{2}$ ) at the $\mathrm{Au}-$ electrolyte interface. We speculate that the binding of $\mathrm{CB}[6]$ to the $\mathrm{Au}$ surface together with its ability to host $\mathrm{CO}_{2}$ acts as a driving force for $\mathrm{CO}_{2}$ accumulation at the electrode surface.

SEIRA spectroscopic experiments in a three-electrode configuration were performed to investigate the behavior of the supramolecular complex on the surface at reductive potentials. To the best of our knowledge, the nature of the interaction as well as the stability of $\mathrm{CB}[6]$ on $\mathrm{Au}$ under electrochemical polarization have not yet been assessed in the literature. SEIRA spectra recorded at various potentials revealed that $\mathrm{CB}[6]$ starts to reversibly desorb from the electrode at $-0.7 \mathrm{~V}$ versus the reversible hydrogen electrode (RHE; Figure 6). This is further confirmed by ex situ XPS measurements (Figure S12). Note that the anchoring of the carbonyl-lined portal of $\mathrm{CB}[6]$ is significantly different to chemisorption through commonly employed thiol groups on $\mathrm{Au}$ that suffer from low electrochemical stability under reductive conditions. ${ }^{68}$ Though several groups have recently reported that multidentate thiol-anchoring provides improved stability of cocatalysts for $\mathrm{CO}_{2}$ reduction, reductive desorption effects were not discussed in detail. ${ }^{18,19}$

As shown in Figure $6 \mathrm{~b}, \mathrm{c}$, the intensity of the $\mathrm{CB}[6] \cdot \mathrm{CO}_{2}$ band started to decline at potentials below ca. $-0.4 \mathrm{~V}$ versus RHE, matching the catalytic onset for $\mathrm{CO}_{2}$ reduction (see below). This observation indicates the reduction of $\mathrm{CO}_{2}$ inside the $\mathrm{Au}$-immobilized $\mathrm{CB}[6]$ cavity. Mere desorption of $\mathrm{CB}[6]$ hosting $\mathrm{CO}_{2}$ at very reducing conditions, which would also cause a decay of the $2333 \mathrm{~cm}^{-1}$ band, can be excluded because the observed SEIRA signals of $\mathrm{CB}[6]$ remain constant at potentials that already afford a significant decrease of the $\mathrm{CB}[6] \cdot \mathrm{CO}_{2}$ band (Figure $6 \mathrm{c}$ ). Therefore, the results suggest that the effects of $\mathrm{CB}[6]$ host-guest chemistry can be exploited for $\mathrm{CO}_{2}$ reduction at least at the desirable low overpotential region between -0.4 and $-0.7 \mathrm{~V}$ versus RHE. Furthermore, the data imply that a part of the remaining surface-bound $\mathrm{CB}[6]$ has an empty cavity at potentials more negative than $-0.8 \mathrm{~V}$ versus RHE.

Plotting the $2343 \mathrm{~cm}^{-1}$ band observed on unmodified $\mathrm{Au}$ surfaces and in the presence of $\mathrm{CB}[6]$ yielded matching trends suggesting that $\mathrm{CO}_{2}$ reduction of "free" $\mathrm{CO}_{2}$ proceeds in both cases in a similar environment (Figure S13). A potential shift of the $2333 \mathrm{~cm}^{-1}$ intensity curve by approximately $40 \mathrm{mV}$ at potential values affording turnover was noted, which may be related to an altered $\mathrm{CO}_{2}$ reduction reaction within the cavity. $\mathrm{CB}[6]$-bound $\mathrm{CO}$ was not detected as expected from the low binding affinity and solubility of $\mathrm{CO}$. Moreover, $\mathrm{CB}[6]$ marker bands in the $\mathrm{CO}_{2}$-purged electrolyte were found to match those in Ar-purged solutions (Figure S14) also at very negative potentials. This indicates that the structure and conformation of $\mathrm{CB}[6]$ is maintained throughout the large potential window and under $\mathrm{CO}_{2}$ binding, suggesting that there is no change in $\mathrm{CO}_{2}$ binding affinity particularly at negative potentials.

Electrocatalysis. Stepped constant-potential electrolysis experiments were performed to monitor the influence of $\mathrm{CB}[6]$ on the activity and selectivity of $\mathrm{CO}_{2}$ reduction on Au. The cell design with online gas sampling was based on recent 

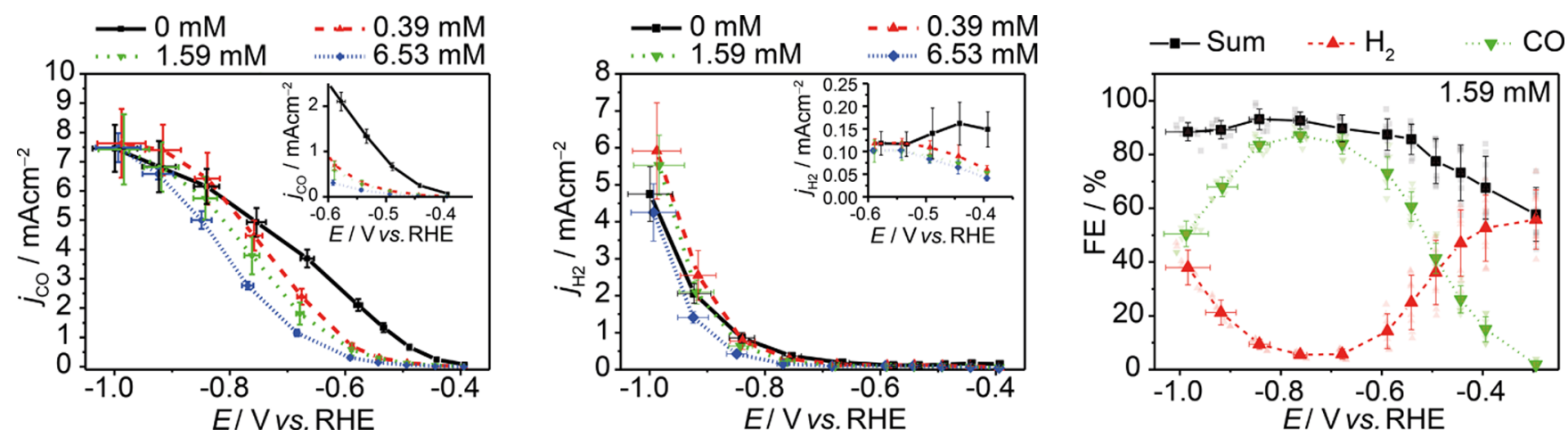

Figure 7. Constant-potential electrolysis at seven potentials with online gas quantification. The data represents averages and standard deviations of at least three independent stepped-chronoamperometry experiments. The $x$ axis error is calculated based on a $\pm 3 \Omega$ change in uncompensated resistance. (a) Partial CO current density $\left(j_{\mathrm{co}}\right)$, (b) partial $\mathrm{H}_{2}$ current density $\left(j_{\mathrm{H} 2}\right)$, and (c) Faradaic efficiency of $1.59 \mathrm{mM} \mathrm{CB}[6]$ measurements.

reports $^{69,70}$ and is described in detail in the Supporting Information (Figures S15-S17). Additional characterization including diffusion layer thickness and electrochemical surface area determination following a recent report for more standardized data acquisition ${ }^{71}$ is also reported in the Supporting Information (Figures S18-S20). The system showed good stability for $12 \mathrm{~h}$ (Figure S21). Figure 7 compares partial current densities at various potentials of $\mathrm{Au}$ electrodes in solutions of $\mathrm{CB}[6]$ of varying concentrations to cover the $\mathrm{CB}[6]$ monolayer and multilayer regimes. The results of unmodified (blank) Au agree with recently published findings. $^{7}$ Self-assembly of $\mathrm{CB}[6]$ prior to catalysis without $\mathrm{CB}[6]$ in the electrolyte solution during electrocatalysis showed marginal differences compared to unfunctionalized $\mathrm{Au}$ electrodes (Figure S22), which is presumably due to a less favorable adsorption equilibrium of $\mathrm{CB}[6]$ at negative applied potentials over the timespan of the electrocatalysis experiments.

In contrast, the presence of $\mathrm{CB}[6]$ in the solution was found to selectively alter the $\mathrm{CO}$ partial current density $\left(j_{\text {co }}\right)$, while the hydrogen evolution current $\left(j_{\mathrm{H} 2}\right)$ remained almost unchanged (Figure 7 ). In the potential window from -0.4 to $-0.8 \mathrm{~V}$ versus $\mathrm{RHE}, j_{\text {co }}$ curves were observed to shift to more negative potentials with increasing $\mathrm{CB}[6]$ concentrations, corresponding to a suppression of $j_{\mathrm{co}}$ with $\mathrm{CB}[6]$ in the solution (Figure 7a; further details of electrocatalysis data in Figures S23-S27). At $0.39 \mathrm{mM} \mathrm{CB}[6]$, an approximately 100 $\mathrm{mV}$ more negative potential was required to achieve a comparable $j_{\text {co }}$ than in the absence of $\mathrm{CB}[6]$. No signals of $\mathrm{CB}[6]$ degradation were observed by nuclear magnetic resonance (NMR) spectroscopy (Figure S28), and ${ }^{13} \mathrm{CO}_{2}$ electrocatalysis experiments yielded exclusively ${ }^{13} \mathrm{CO}$ (Figure S29). Upon decreasing the potential to be more negative than $-0.8 \mathrm{~V}$ versus RHE, a convergence of the $j_{\mathrm{CO}}$ in the absence and presence of $\mathrm{CB}[6]$ with different concentrations was observed (Figure $7 \mathrm{a}$ ). This observation can be rationalized by the potential-induced desorption of $\mathrm{CB}[6]$ from the surface starting to occur at potentials more negative than $-0.7 \mathrm{~V}$ versus RHE (Figure 6c).

Mechanistic Interpretation. The experimental data demonstrate that the electrocatalytic reduction of $\mathrm{CO}_{2}$ on $\mathrm{Au}$ has been effectively altered by $\mathrm{CB}[6]$ encapsulation. This effect can be explained on a molecular basis through the macrocycle's impact particularly on the rate-determining step (RDS) of the catalytic process. In this respect, an initial electron transfer to $\mathrm{CO}_{2}$ to form a $\mathrm{Au}-\mathrm{COO}^{-}$species and a proton-coupled electron transfer to form directly a $\mathrm{Au}-$ $\mathrm{COOH}$ species are often discussed as possible candidates. ${ }^{4,64,72-74}$ Both cases would yield a Tafel slope of 118 $\mathrm{mV} \operatorname{dec}^{-1}$ based on the initial electron transfer as the ratelimiting step, which matches our Tafel slopes of approximately $120 \mathrm{mV} \mathrm{dec}^{-1}$ for unmodified and $\mathrm{CB}[6]$-coated Au surfaces (Figure S30). Thus, the unaffected Tafel slopes in the presence of $\mathrm{CB}[6]$ as well as the fact that only $\mathrm{CO}$ is generated allow us to draw the conclusion that the macrocycle-mediated catalytic $\mathrm{CO}_{2}$ reduction likely proceeds via the same elementary steps as on bare $\mathrm{Au}$. The altered catalytic performance however suggests that the new reaction environment induced by $\mathrm{CB}[6]$ has significantly altered the kinetics of relevant reaction steps. This can be rationalized by an altered energy landscape for the reaction through specific interactions on $\mathrm{CO}_{2}$ and * $\mathrm{COO}^{-}$within $\mathrm{CB}[6]$ compared to the blank $\mathrm{Au}$ interface. This is provided by the following qualitative arguments:

(1) The hydrophobic nature of the cavity lowers the availability of water molecules to stabilize surfacebound intermediates through hydrogen bond formation. Previous molecular dynamics simulations suggest approximately 3-4 water molecules in the cavity of solubilized $\mathrm{CB}[6]$ without a guest in the aqueous environment. $^{75}$ In line with this report, our MD simulations show that an average of less than one (0.62) water molecule is present within the space defined by the $\mathrm{CB}[6]$ carbonyl oxygen rims when $\mathrm{CO}_{2}$ or $\mathrm{CO}$ is adsorbed in the $\mathrm{CB}[6]$ cavity.

(2) Cations such as $\mathrm{K}^{+}$have previously been shown to have a large effect on the $\mathrm{CO}_{2}$ reduction reaction by stabilizing intermediates exhibiting a permanent dipole moment. ${ }^{30}$ However, MD simulations show that the inclusion of $\mathrm{K}^{+}$into $\mathrm{CB}[6]$ is energetically unfavorable (Figure S3), and DFT-optimized structures of $\mathrm{CB}[6]$ with $\mathrm{K}^{+}$on a Au surface suggest that the distance between $\mathrm{K}^{+}$and the encapsulated surface-bound intermediate $\mathrm{COOH}$ is too large for a stabilizing interaction (Figure 8).

(3) Without further modifications, CB is known to stabilize electron-deficient guests via hydrophobic interactions in the cavity and electrostatic interactions at the carbonyl rim. Hence, direct stabilization of a charged intermediate by the $\mathrm{CB}[6]$ cavity is likely not being provided. ${ }^{26}$

(4) DFT and MD calculations presented above revealed an approximately $7 \mathrm{kcal} \mathrm{mol}^{-1}$ free-energy difference of $\mathrm{CO}_{2}$ in $\mathrm{CB}[6]$ compared to being freely diffusing in 


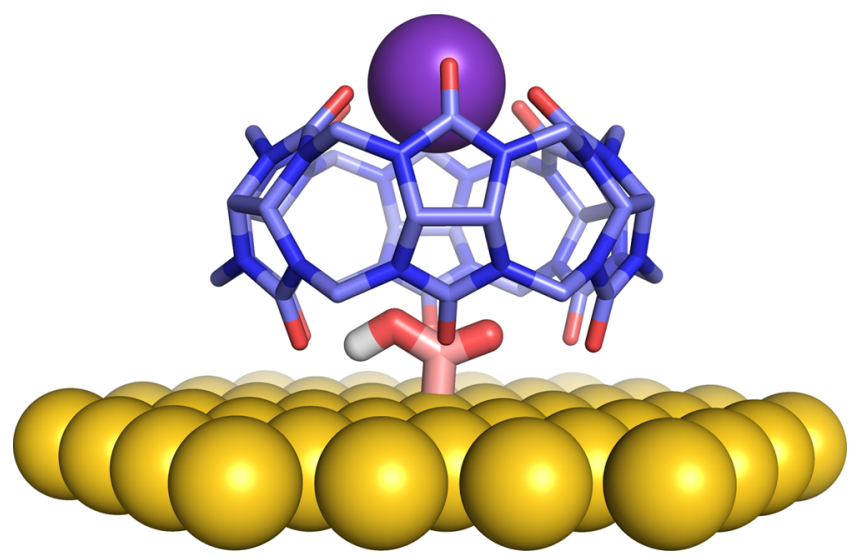

Figure 8. DFT calculation-derived model of the $\mathrm{Au}-\mathrm{COOH}$ intermediate in the $\mathrm{CB}[6]$ cavity on the Au surface. $\mathrm{K}^{+}$is coordinated to the carbonyl lined rim of $\mathrm{CB}[6]$. Color coding: purple: $\mathrm{K}^{+}$, red: $\mathrm{O}$, yellow: $\mathrm{Au}$, light blue: $\mathrm{C}(\mathrm{CB}[6])$, dark blue: $\mathrm{N}$, white: $\mathrm{H}$ (not shown for $\mathrm{CB}[6]$ for increased clarity), and light red: surface-bound $\mathrm{C}$.

solution (Figure 3 and Table S1). This indicates that $\mathrm{CO}_{2}$ is stabilized within $\mathrm{CB}[6]$ and thus exhibits a reduced capability for subsequent reactions without additional stabilization of the reaction intermediate.

The altered environment within $\mathrm{CB}[6]$ will eventually affect the thermodynamics and kinetics of formation of encapsulated surface-bound species. To gauge such effects, DFT calculations were performed particularly for the $\mathrm{Au}-\mathrm{COOH}$ species formation (details in the Supporting Information, Figures $\mathrm{S} 31$ and S32). Calculations for $\mathrm{Au}-\mathrm{COO}^{-}$were not possible due the high level of complexity regarding the uncompensated charge. For $\mathrm{CO}_{2}$, the results show a horizontally aligned molecule in the vicinity of the bare Au surface (Figure S32), whereas a more perpendicular orientation was found within $\mathrm{CB}[6]$, suggesting that inclusion affords a different stabilization of the substrate near the electrode surface.

Next, the reaction free-energy difference $\left(\Delta \Delta_{R} G\right)$ of the reaction from $\mathrm{Au}-\mathrm{CO}_{2}$ to $\mathrm{Au}-\mathrm{COOH}$ within $\mathrm{CB}[6]$ and at the blank Au surface was calculated. An increase of $\sim 8 \mathrm{kcal}$ $\mathrm{mol}^{-1}(0.36 \mathrm{eV})$ was determined for the reaction proceeding in $\mathrm{CB}[6]$ compared to blank Au (Table S2). Thus, the calculation provides evidence for a notably increased energy required for the reaction upon encapsulation, which is proposed to result from the absence of solvent/cation-mediated stabilization of the product, that is, $\mathrm{Au}-\mathrm{COOH}$ as discussed qualitatively above as well as from additional stabilization of the substrate $\mathrm{CO}_{2}$ within $\mathrm{CB}[6]$. This effect is expected to be even more pronounced when considering $\mathrm{Au}-\mathrm{COO}^{-}$, which should be energetically higher due to the absent charge compensation by the proton as well as the lack of other electrostatic interactions in the cavity as discussed above.

As a result, a higher-energy RDS is expected, leading to an overall decrease in $j_{\mathrm{CO}}$ (at the same applied potential) and therefore providing a molecular basis for explaining the increased overpotential required to reduce $\mathrm{CO}_{2}$ inside the $\mathrm{CB}[6]$ cavity. In agreement, at a $0.39 \mathrm{mM} \mathrm{CB}[6]$ concentration corresponding to a quasi-monolayer of $\mathrm{CB}[6]$ on $\mathrm{Au}$, an indicative shift in $j_{\mathrm{co}}$ of the $\mathrm{CB}[6]$-modified electrode by $\sim 100 \mathrm{mV}$ as aforementioned was observed. In this context, increasing the $\mathrm{CB}[6]$ concentration to $1.59 \mathrm{mM}$ has little effect as the surface coverage is not significantly increased as demonstrated by QCM and SEIRA measurements (Figure
5). However, at $6.53 \mathrm{mM} \mathrm{CB}[6]$ where multilayer formation occurs, further, stronger suppression of the $\mathrm{CO}$ current density is apparent. Thus, for high $\mathrm{CB}[6]$ concentrations, $j_{\mathrm{CO}}$ is likely governed by additional factors, such as a hindered $\mathrm{CO}_{2}$ uptake into $\mathrm{CB}[6]$ and $\mathrm{CO}$ release due to the adsorbed multilayers corresponding to an effective blocking of the electrode surface.

Host-Guest Design Criteria for Electrocatalysis. The rational manipulation of the heterogeneous interfacial catalytic process by creating well-defined reaction environments opens up promising avenues to selectively alter the catalytic transformation to desired outcomes in the future. Based on our findings, we propose three design criteria to rationally achieve an improved molecular cocatalyst system for $\mathrm{CO}_{2}$ reduction to $\mathrm{CO}$ :

(1) The induced reaction environment should be modulated to selectively stabilize the surface-bound intermediate $\mathrm{COO}^{-} / \mathrm{COOH}$ to help break scaling relationships. Recent publications discuss the ability of amines ${ }^{76}$ and amides ${ }^{18,19,77}$ in a ligand construct as well as imidazolium-based ionic liquids ${ }^{78,79}$ to stabilize $\mathrm{CO}_{2}$ reduction intermediates via hydrogen bonding and/or electrostatic interactions on bare electrodes. In this respect, we envision that secondary guests within the $\mathrm{CB}$ cavity might be used to accommodate specific functional groups to selectively tune the active site environment. The larger $\mathrm{CB}[8]$ is able to incorporate two molecules within its cavity, which offers a large degree of tunability of the electrostatic and chemical environment within the cavity. $^{26}$

(2) The inclusion of the substrate $\mathrm{CO}_{2}$ should facilitate consecutive reactions, for example, by enabling specific interactions of $\mathrm{CO}_{2}$ with the cavity analogous to enzyme active sites. We observed a $10 \mathrm{~cm}^{-1}$ shift toward lower wavenumbers for $\mathrm{CO}_{2}$ inside the $\mathrm{CB}[6]$ cavity. This may suggest a decreased bond order of $\mathrm{CO}_{2}$. Nevertheless, this effect might not be dominant in the presented system due to the lack of stabilization of a key intermediate $\left(\mathrm{COOH} / \mathrm{COO}^{-}\right)$. The probing of interactions of $\mathrm{CO}_{2}$ with a secondary guest in the $\mathrm{CB}$ cavity via vibrational spectroscopy might enable systematic studies of host-substrate binding prior to catalytic turnover.

(3) The kinetics of $\mathrm{CO}_{2}$ uptake and $\mathrm{CO}$ release needs to be sufficiently fast to accomplish highly catalytic activities. A simple model calculation (see the Supporting Information) suggests that ingress and egress kinetics of $\mathrm{CO}_{2}$ and $\mathrm{CO}$, respectively, should be higher than 20 $\mathrm{s}^{-1}$ to obtain $>5 \mathrm{~mA} \mathrm{~cm}{ }^{-2}$ for $j_{\mathrm{CO}}$. A high binding constant for $\mathrm{CO}_{2}$ and low binding constant for $\mathrm{CO}$ should be maintained. The binding constant is defined as the ratio of ingress and egress kinetics, ${ }^{46}$ and the egress kinetics for $\mathrm{CO}_{2}$ and ingress kinetics for $\mathrm{CO}$ should therefore be slow. While enzymes have perfected this independent tuning of complexation kinetics and thermodynamics, it remains difficult to realize this in synthetic systems. The use of cations as "lids" for the CB portals has been suggested to influence host-guest complex formation kinetics. ${ }^{45}$ This might enable a pathway through a variation of cations in the electrolyte solution to specifically alter the kinetics of substrate inclusion or product release. Moreover, addition of competitively binding non-redox-active guests could 
allow for further rational tuning of $\mathrm{CO}_{2}$ ingress/egress kinetics by subtly changing the host-guest equilibria as well as electronics and sterics.

The manifold of new pathways to pursue shows that the $\mathrm{CB}[n]-$ Au hybrid system provides us with proposed measures and a modular platform to selectively tune different reaction steps of the heterogeneous $\mathrm{CO}_{2}$ reduction at $\mathrm{Au}$ surfaces and to mechanistically explore electrocatalysis at the inorganicorganic interfaces. This allows for detailed investigations of the reaction mechanism by rational experimental design toward a complete understanding of the process. Such knowledge is a major prerequisite for the development of next generation electrocatalysts.

\section{CONCLUSIONS}

We present the concept of surface-adsorbed supramolecular host-guest chemistry in heterogeneous electrocatalysis. The combined spectroscopic, analytical, and electrocatalytic results suggest that $\mathrm{CO}_{2}$ is captured within the cavity of the supramolecular host-molecule $\mathrm{CB}[6]$ and electrocatalytically reduced inside the cavity when adsorbed on the gold surface. An increased concentration of $\mathrm{CO}_{2}$ is observed at the electrode-electrolyte interface due to the binding of $\mathrm{CB}[6] \cdot \mathrm{CO}_{2}$.

The confinement of $\mathrm{CO}_{2}$ reduction into $\mathrm{CB}[6]$ nanocavities enables molecular tunablity of the local chemical environment on the electrocatalyst surface. The presented data indicates that the $\mathrm{CB}[6]$ complexation strongly and selectively affects the electrocatalytic reduction of $\mathrm{CO}_{2}$ to $\mathrm{CO}$, while the hydrogen evolution activity remains essentially unchanged. The resultant hybrid organic-inorganic composite can thus be regarded as a model system for synthetic cavity-based heterogeneous electrocatalysts. Notably, a plethora of different research fields spanning from metal-organic frameworks ${ }^{80,81}$ and covalent-organic frameworks ${ }^{82}$ to molecular catalysis ${ }^{83-86}$ and synthetic biology ${ }^{87}$ are also heavily focused on tuning the local environment and coordination spheres around a catalytic active site. The development of such model systems and analytical methodology as presented here may help us to gain insight in this complex and important field of research. In the context of $\mathrm{CO}_{2}$ reduction electrocatalysis, this may offer new routes to overcome scaling relationships and rationally tune the selectivity and activity of electrodes also beyond Au. Thus, this concept bridges the gap between enzymatic, molecular, and heterogeneous catalysis and may open up new avenues for utilizing fine-tuned supramolecular units as synthetic catalytic pockets.

\section{ASSOCIATED CONTENT}

\section{S Supporting Information}

The Supporting Information is available free of charge at https://pubs.acs.org/doi/10.1021/acscatal.9b04221.

Detailed experimental procedures, additional transmission IR, SEIRA, QCM, XPS, MD, DFT, fluorescence, electrochemical characterization and electrocatalysis results (PDF)

\section{AUTHOR INFORMATION}

\section{Corresponding Authors}

*E-mail: oas23@cam.ac.uk (O.A.S.).

*E-mail: reisner@ch.cam.ac.uk (E.R.).

\section{ORCID}

Andreas Wagner: 0000-0003-4464-4345

István Szabó: 0000-0002-3700-3614

Khaleel I. Assaf: 0000-0003-4331-8492

Steven J. Barrow: 0000-0001-6417-1800

Mohamed Al-Hada: 0000-0002-2913-9490

Nikolay Kornienko: 0000-0001-7193-2428

Moritz F. Kuehnel: 0000-0001-8678-3779

Edina Rosta: 0000-0002-9823-4766

Ingo Zebger: 0000-0002-6354-3585

Werner M. Nau: 0000-0002-7654-6232

Oren A. Scherman: 0000-0001-8032-7166

Erwin Reisner: 0000-0002-7781-1616

\section{Present Addresses}

K.H.L.: Fakultät für Chemie und Lebensmittelchemie, Technische Universität Dresden, 01062 Dresden, Germany.

-M.F.K.: Department of Chemistry, Swansea University, College of Science, Singleton Park, Swansea SA2 8PP, U.K.

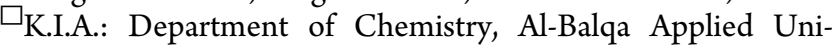
versity, Al-Salt 19117, Jordan

${ }^{\&}$ S.J.B.: School of Applied Chemistry and Environmental Science, RMIT University, Melbourne, 3000, Victoria, Australia.

${ }^{\mathbb{I}}$ N.K. and N.H.: Department of Chemistry, Université de Montréal, Roger-Gaudry Building, Montreal, Quebec, H3C 3J7, Canada.

\section{Author Contributions}

O.W. and K.H.L. contributed equally to this work.

\section{Notes}

The authors declare no competing financial interest. Additional data related to this publication are available at the University of Cambridge data repository (https://doi.org/10. 17863/CAM.46170).

\section{ACKNOWLEDGMENTS}

We gratefully acknowledge financial support from the Christian Doppler Research Association, Austrian Federal Ministry for Digital and Economic Affairs, National Foundation for Research, Technology and Development, OMV Group (to A.W., M.F.K., and Er.R.), EU ERC Consolidator grant "MatEnSAP" (no. 68283 to N.H. and Er.R.) and Starting Grant "BioNet" (no. 757850 to Ed.R.), Royal Society Newton International Fellowship (no. NF160054 to N.K.), European Commission for Marie Curie Fellowships (NANOSPHERE, no. 658360 to S.J.B.; VSHER, no. 701192 to K.H.L.; and ESTIMABLeNANO, no. 706425 to K.S.), EPSRC (nos. EP/ R013012/1 and EP/N020669/1 to Ed.R. and no. EP/ L027151/1 for O.A.S.), and DFG, Deutsche Forschungsgemeinschaft/German Research Foundation (to K.I.A. and W.M.N.) as well as funding under Germany's Excellence Strategy - EXC 2008/1 - 390540038 (UniSysCat) (i.a. to I.Z.). We are also grateful to the U.K. Materials and Molecular Modelling Hub for computational resources, which is partially funded by EPSRC (no. EP/P020194/1). We would like to thank Mr. Simon Dowe for the help in the design and manufacturing of the electrochemical cell, Dr. Guanglu Wu and Dr. Annika Eisenschmidt for their help with NMR spectroscopy, Dr. Jade Alexis McCune for a $\mathrm{CB}[6]$ sample, and Mr. Dénes Berta for discussion regarding DFT computations. 


\section{REFERENCES}

(1) Qiao, J.; Liu, Y.; Hong, F.; Zhang, J. A Review of Catalysts for the Electroreduction of Carbon Dioxide to Produce Low-Carbon Fuels. Chem. Soc. Rev. 2014, 43, 631-675.

(2) Lewis, N. S.; Nocera, D. G. Powering the Planet: Chemical Challenges in Solar Energy Utilization. Proc. Natl. Acad. Sci. USA 2006, 103, 15729-15735.

(3) Whipple, D. T.; Kenis, P. J. A. Prospects of $\mathrm{CO}_{2}$ Utilization via Direct Heterogeneous Electrochemical Reduction. J. Phys. Chem. Lett. 2010, 1, 3451-3458.

(4) Kortlever, R.; Shen, J.; Schouten, K. J. P.; Calle-Vallejo, F.; Koper, M. T. M. Catalysts and Reaction Pathways for the Electrochemical Reduction of Carbon Dioxide. J. Phys. Chem. Lett. 2015, 6, 4073-4082.

(5) Jhong, H.-R. M.; Ma, S.; Kenis, P. J. Electrochemical Conversion of $\mathrm{CO}_{2}$ to Useful Chemicals: Current Status, Remaining Challenges, and Future Opportunities. Curr. Opin. Chem. Eng. 2013, 2, 191-199.

(6) Hori, Y.; Murata, A.; Kikuchi, K.; Suzuki, S. Electrochemical Reduction of Carbon Dioxide to Carbon Monoxide at a Gold Electrode in Aqueous Potassium Hydrogen Carbonate. J. Chem. Soc., Chem. Commun. 1987, 728-729.

(7) Cave, E. R.; Montoya, J. H.; Kuhl, K. P.; Abram, D. N.; Hatsukade, T.; Shi, C.; Hahn, C.; Nørskov, J. K.; Jaramillo, T. F. Electrochemical $\mathrm{CO}_{2}$ Reduction on Au Surfaces: Mechanistic Aspects Regarding the Formation of Major and Minor Products. Phys. Chem. Chem. Phys. 2017, 19, 15856-15863.

(8) Chen, Y.; Li, C. W.; Kanan, M. W. Aqueous $\mathrm{CO}_{2}$ Reduction at Very Low Overpotential on Oxide-Derived Au Nanoparticles. J. Am. Chem. Soc. 2012, 134, 19969-19972.

(9) Hansen, H. A.; Varley, J. B.; Peterson, A. A.; Nørskov, J. K. Understanding Trends in the Electrocatalytic Activity of Metals and Enzymes for $\mathrm{CO}_{2}$ Reduction to CO. J. Phys. Chem. Lett. 2013, 4, 388-392.

(10) Zhu, W.; Zhang, Y.-J.; Zhang, H.; Lv, H.; Li, Q.; Michalsky, R.; Peterson, A. A.; Sun, S. Active and Selective Conversion of $\mathrm{CO}_{2}$ to CO on Ultrathin Au Nanowires. J. Am. Chem. Soc. 2014, 136, 1613216135 .

(11) Shi, C.; Hansen, H. A.; Lausche, A. C.; Nørskov, J. K. Trends in Electrochemical $\mathrm{CO}_{2}$ Reduction Activity for Open and Close-Packed Metal Surfaces. Phys. Chem. Chem. Phys. 2014, 16, 4720-4727.

(12) Li, Y.; Sun, Q. Recent Advances in Breaking Scaling Relations for Effective Electrochemical Conversion of $\mathrm{CO}_{2}$. Adv. Energy Mater. 2016, 6, 1600463.

(13) Kim, D.; Resasco, J.; Yu, Y.; Asiri, A. M.; Yang, P. Synergistic Geometric and Electronic Effects for Electrochemical Reduction of Carbon Dioxide Using Gold-Copper Bimetallic Nanoparticles. Nat. Commun. 2014, 5, 4948.

(14) Torelli, D. A.; Francis, S. A.; Crompton, J. C.; Javier, A.; Thompson, J. R.; Brunschwig, B. S.; Soriaga, M. P.; Lewis, N. S. Nickel-Gallium-Catalyzed Electrochemical Reduction of $\mathrm{CO}_{2}$ to Highly Reduced Products at Low Overpotentials. ACS Catal. 2016, 6, 2100-2104.

(15) Calle-Vallejo, F.; Loffreda, D.; Koper, M. T. M.; Sautet, P. Introducing Structural Sensitivity into Adsorption-Energy Scaling Relations by Means of Coordination Numbers. Nat. Chem. 2015, 7, 403-410.

(16) Fang, Y.; Flake, J. C. Electrochemical Reduction of $\mathrm{CO}_{2}$ at Functionalized Au Electrodes. J. Am. Chem. Soc. 2017, 139, 33993405 .

(17) Xie, M. S.; Xia, B. Y.; Li, Y.; Yan, Y.; Yang, Y.; Sun, Q.; Chan, S. H.; Fisher, A.; Wang, X. Amino Acid Modified Copper Electrodes for the Enhanced Selective Electroreduction of Carbon Dioxide towards Hydrocarbons. Energy Environ. Sci. 2016, 9, 1687-1695.

(18) Gong, M.; Cao, Z.; Liu, W.; Nichols, E. M.; Smith, P. T.; Derrick, J. S.; Liu, Y.-S.; Liu, J.; Wen, X.; Chang, C. J. Supramolecular Porphyrin Cages Assembled at Molecular-Materials Interfaces for Electrocatalytic CO Reduction. ACS Cent. Sci. 2017, 3, 1032-1040.

(19) Cao, Z.; Zacate, S. B.; Sun, X.; Liu, J.; Hale, E. M.; Carson, W. P.; Tyndall, S. B.; Xu, J.; Liu, X.; Liu, X.; Song, C.; Luo, J.; Cheng, M.-
J.; Wen, X.; Liu, W. Tuning Gold Nanoparticles with Chelating Ligands for Highly Efficient Electrocatalytic $\mathrm{CO}_{2}$ Reduction. Angew. Chem., Int. Ed. 2018, 57, 12675-12679.

(20) Cao, Z.; Kim, D.; Hong, D.; Yu, Y.; Xu, J.; Lin, S.; Wen, X.; Nichols, E. M.; Jeong, K.; Reimer, J. A.; Yang, P.; Chang, C. J. A Molecular Surface Functionalization Approach to Tuning Nanoparticle Electrocatalysts for Carbon Dioxide Reduction. J. Am. Chem. Soc. 2016, 138, 8120-8125.

(21) Shin, W.; Lee, S. H.; Shin, J. W.; Lee, S. P.; Kim, Y. Highly Selective Electrocatalytic Conversion of $\mathrm{CO}_{2}$ to $\mathrm{CO}$ at $-0.57 \mathrm{~V}$ (NHE) by Carbon Monoxide Dehydrogenase from Moorella thermoacetica. J. Am. Chem. Soc. 2003, 125, 14688-14689.

(22) Parkin, A.; Seravalli, J.; Vincent, K. A.; Ragsdale, S. W.; Armstrong, F. A. Rapid and Efficient Electrocatalytic $\mathrm{CO}_{2} / \mathrm{CO}$ Interconversions by Carboxydothermus Hydrogenoformans $\mathrm{CO}$ Dehydrogenase I on an Electrode. J. Am. Chem. Soc. 2007, 129, 10328-10329.

(23) Robinson, W. E.; Bassegoda, A.; Reisner, E.; Hirst, J. OxidationState-Dependent Binding Properties of the Active Site in a MoContaining Formate Dehydrogenase. J. Am. Chem. Soc. 2017, 139, 9927-9936.

(24) Shi, J.; Jiang, Y.; Jiang, Z.; Wang, X.; Wang, X.; Zhang, S.; Han, P.; Yang, C. Enzymatic Conversion of Carbon Dioxide. Chem. Soc Rev. 2015, 44, 5981-6000.

(25) Can, M.; Armstrong, F. A.; Ragsdale, S. W. Structure, Function, and Mechanism of the Nickel Metalloenzymes, CO Dehydrogenase, and Acetyl-CoA Synthase. Chem. Rev. 2014, 114, 4149-4174.

(26) Barrow, S. J.; Kasera, S.; Rowland, M. J.; del Barrio, J.; Scherman, O. A. Cucurbituril-Based Molecular Recognition. Chem. Rev. 2015, 115, 12320-12406.

(27) You, H.; Wu, D.; Chen, Z.; Sun, F.; Zhang, H.; Chen, Z.; Cao, M.; Zhuang, W.; Cao, R. Highly Active and Stable Water Splitting in Acidic Media Using a Bifunctional Iridium/Cucurbit[6]uril Catalyst. ACS Energy Lett. 2019, 4, 1301-1307.

(28) Kaifer, A. E. Toward Reversible Control of Cucurbit $[n]$ uril Complexes. Acc. Chem. Res. 2014, 47, 2160-2167.

(29) Mitkina, T. V.; Zakharchuk, N. F.; Naumov, D. Y.; Gerasko, O. A.; Fenske, D.; Fedin, V. P. Syntheses, Structures, and Electrochemical Properties of Inclusion Compounds of Cucurbit[8] uril with Cobalt(III) and Nickel(II) Complexes. Inorg. Chem. 2008, 47, 67486755.

(30) Assaf, K. I.; Nau, W. M. Cucurbiturils: From Synthesis to HighAffinity Binding and Catalysis. Chem. Soc. Rev. 2015, 44, 394-418.

(31) Florea, M.; Nau, W. M. Strong Binding of Hydrocarbons to Cucurbituril Probed by Fluorescent Dye Displacement: A Supramolecular Gas-Sensing Ensemble. Angew. Chem., Int. Ed. 2011, 50, 9338-9342.

(32) An, Q.; Li, G.; Tao, C.; Li, Y.; Wu, Y.; Zhang, W. A General and Efficient Method to Form Self-Assembled Cucurbit $[n]$ uril Monolayers on Gold Surfaces. Chem. Commun. 2008, 36, 1989-1991.

(33) Shin, J. W.; Bertocci, U.; Stafford, G. R. Stress Response to Surface Alloying and Dealloying during Underpotential Deposition of $\mathrm{Pb}$ on (111)-Textured Au. J. Phys. Chem. C 2010, 114, 7926-7932.

(34) Rojas, M. T.; Königer, R.; Stoddart, J. F.; Kaifer, A. E. Supported Monolayers Containing Preformed Binding Sites. Synthesis and Interfacial Binding Properties of a Thiolated $\beta$-Cyclodextrin Derivative. J. Am. Chem. Soc. 1995, 117, 336-343.

(35) Yao, Y.; Xue, M.; Zhang, Z.; Zhang, M.; Wang, Y.; Huang, F. Gold Nanoparticles Stabilized by an Amphiphilic Pillar[5]Arene: Preparation, Self-Assembly into Composite Microtubes in Water and Application in Green Catalysis. Chem. Sci. 2013, 4, 3667.

(36) Kim, H.; Kim, Y.; Yoon, M.; Lim, S.; Park, S. M.; Seo, G.; Kim, K. Highly Selective Carbon Dioxide Sorption in an Organic Molecular Porous Material. J. Am. Chem. Soc. 2010, 132, 12200-12202.

(37) Mohan, M.; Suzuki, T.; Nair, A. K.; Pillai, S.; Warrier, K. G. K.; Hareesh, U. S.; Nair, B. N.; Gale, J. D. Surface Modification Induced Enhanced $\mathrm{CO}_{2}$ Sorption in Cucurbit[6]uril, an Organic Porous Material. Phys. Chem. Chem. Phys. 2017, 19, 25564-25573. 
(38) Falk, M.; Miller, A. G. Infrared Spectrum of Carbon Dioxide in Aqueous Solution. Vib. Spectrosc. 1992, 4, 105-108.

(39) Mock, W. L.; Shih, N. Y. Structure and Selectivity in HostGuest Complexes of Cucurbituril. J. Org. Chem. 1986, 51, 44404446.

(40) Pan, S.; Saha, R.; Mandal, S.; Mondal, S.; Gupta, A.; FernándezHerrera, M. A.; Merino, G.; Chattaraj, P. K. Selectivity in Gas Adsorption by Molecular Cucurbit[6]uril. J. Phys. Chem. C 2016, 120, 13911-13921.

(41) Ghale, G.; Nau, W. M. Dynamically Analyte-Responsive Macrocyclic Host-Fluorophore Systems. Acc. Chem. Res. 2014, 47, $2150-2159$

(42) Palma, A.; Artelsmair, M.; Wu, G.; Lu, X.; Barrow, S. J.; Uddin, N.; Rosta, E.; Masson, E.; Scherman, O. A. Cucurbit[7]uril as a Supramolecular Artificial Enzyme for Diels-Alder Reactions. Angew. Chem., Int. Ed. 2017, 56, 15688-15692.

(43) Lee, T.-C.; Scherman, O. A. Formation of Dynamic Aggregates in Water by Cucurbit[5] uril Capped with Gold Nanoparticles. Chem. Commun. 2010, 46, 2438-2440.

(44) McCune, J. A.; Kunz, S.; Olesińska, M.; Scherman, O. A. DESolution of CD and CB Macrocycles. Chem. - Eur. J. 2017, 23, 8601-8604.

(45) Jeon, Y.-M.; Kim, J.; Whang, D.; Kim, K. Molecular Container Assembly Capable of Controlling Binding and Release of Its Guest Molecules: Reversible Encapsulation of Organic Molecules in Sodium Ion Complexed Cucurbituril. J. Am. Chem. Soc. 1996, 118, 97909791.

(46) Márquez, C.; Hudgins, R. R.; Nau, W. M. Mechanism of HostGuest Complexation by Cucurbituril. J. Am. Chem. Soc. 2004, 126, 5806-5816.

(47) Murata, A.; Hori, Y. Product Selectivity Affected by Cationic Species in Electrochemical Reduction of $\mathrm{CO}_{2}$ and $\mathrm{CO}$ at a $\mathrm{Cu}$ Electrode. Bull. Chem. Soc. Jpn 1991, 64, 123-127.

(48) Kyriacou, G. Z.; Anagnostopoulos, A. K. Influence $\mathrm{CO}_{2}$ Partial Pressure and the Supporting Electrolyte Cation on the Product Distribution in $\mathrm{CO}_{2}$ Electroreduction. J. Appl. Electrochem. 1993, 23, 483-486.

(49) Thorson, M. R.; Siil, K. I.; Kenis, P. J. A. Effect of Cations on the Electrochemical Conversion of $\mathrm{CO}_{2}$ to CO. J. Electrochem. Soc. 2012, 160, F69-F74.

(50) Resasco, J.; Chen, L. D.; Clark, E.; Tsai, C.; Hahn, C.; Jaramillo, T. F.; Chan, K.; Bell, A. T. Promoter Effects of Alkali Metal Cations on the Electrochemical Reduction of Carbon Dioxide. J. Am. Chem. Soc. 2017, 139, 11277-11287.

(51) Kuhl, K. P.; Hatsukade, T.; Cave, E. R.; Abram, D. N.; Kibsgaard, J.; Jaramillo, T. F. Electrocatalytic Conversion of Carbon Dioxide to Methane and Methanol on Transition Metal Surfaces. J. Am. Chem. Soc. 2014, 136, 14107-14113.

(52) Kim, D.; Kley, C. S.; Li, Y.; Yang, P. Copper Nanoparticle Ensembles for Selective Electroreduction of $\mathrm{CO}_{2}$ to $\mathrm{C}_{2}-\mathrm{C}_{3}$ Products. Proc. Natl. Acad. Sci. 2017, 114, 10560-10565.

(53) Sauerbrey, G. Verwendung von Schwingquarzen Zur Waegung Duenner Schichten Und Zur Mikrowaegung. Z. Phys. 1959, 155, 206-222.

(54) Singh, K.; Blanford, C. F. Electrochemical Quartz Crystal Microbalance with Dissipation Monitoring: A Technique to Optimize Enzyme Use in Bioelectrocatalysis. Chem CatChem 2014, 6, 921-929.

(55) Dixon, M. C. Quartz Crystal Microbalance with Dissipation Monitoring: Enabling Real-Time Characterization of Biological Materials and Their Interactions. J. Biomol. Tech. 2008, 19, 151-158.

(56) Notley, S. M.; Eriksson, M.; Wågberg, L. Visco-Elastic and Adhesive Properties of Adsorbed Polyelectrolyte Multilayers Determined in Situ with QCM-D and AFM Measurements. J. Colloid Interface Sci. 2005, 292, 29-37.

(57) Blanco, E.; Quintana, C.; Hernández, L.; Hernández, P. Atomic Force Microscopy Study of New Sensing Platforms: Cucurbit $[n]$ uril $(n=6,7)$ on Gold. Electroanalysis 2013, 25, 263-268.

(58) Heo, J.; Kim, J.; Whang, D.; Kim, K. Columnar OneDimensional Coordination Polymer Formed with a Metal Ion and a
Host-Guest Complex as Building Blocks: Potassium Ion Complexed Cucurbituril. Inorg. Chim. Acta 2000, 297, 307-312.

(59) Ni, X.-L.; Xiao, X.; Cong, H.; Liang, L.-L.; Cheng, K.; Cheng, X.-J.; Ji, N.-N.; Zhu, Q.-J.; Xue, S.-F.; Tao, Z. Cucurbit $[n]$ uril-Based Coordination Chemistry: From Simple Coordination Complexes to Novel Poly-Dimensional Coordination Polymers. Chem. Soc. Rev. 2013, 42, 9480.

(60) Osawa, M.; Ataka, K.-I.; Ikeda, M.; Uchihara, H.; Nanba, R. Surface Enhanced Infrared Absorption Spectroscopy. Anal. Sci. 1991, 7, 503-506.

(61) Wisitruangsakul, N.; Zebger, I.; Ly, K. H.; Murgida, D. H.; Ekgasit, S.; Hildebrandt, P. Redox-Linked Protein Dynamics of Cytochrome c Probed by Time-Resolved Surface Enhanced Infrared Absorption Spectroscopy. Phys. Chem. Chem. Phys. 2008, 10, 52765286.

(62) Chikkaraddy, R.; de Nijs, B.; Benz, F.; Barrow, S. J.; Scherman, O. A.; Rosta, E.; Demetriadou, A.; Fox, P.; Hess, O.; Baumberg, J. J. Single-Molecule Strong Coupling at Room Temperature in Plasmonic Nanocavities. Nature 2016, 535, 127-130.

(63) Osawa, M. Surface-Enhanced Infrared Absorption. In NearField Optics and Surface Plasmon Polaritons; Springer Berlin Heidelberg: Berlin, Heidelberg, 2001; pp 163-187.

(64) Wuttig, A.; Yaguchi, M.; Motobayashi, K.; Osawa, M.; Surendranath, Y. Inhibited Proton Transfer Enhances Au-Catalyzed $\mathrm{CO}_{2}$-to-Fuels Selectivity. Proc. Natl. Acad. Sci. 2016, 113, E4585$\mathrm{E} 4593$.

(65) Wuttig, A.; Liu, C.; Peng, Q.; Yaguchi, M.; Hendon, C. H.; Motobayashi, K.; Ye, S.; Osawa, M.; Surendranath, Y. Tracking a Common Surface-Bound Intermediate during $\mathrm{CO}_{2}$-to-Fuels Catalysis. ACS Cent. Sci. 2016, 2, 522-528.

(66) Dunwell, M.; Lu, Q.; Heyes, J. M.; Rosen, J.; Chen, J. G.; Yan, Y.; Jiao, F.; Xu, B. The Central Role of Bicarbonate in the Electrochemical Reduction of Carbon Dioxide on Gold. J. Am. Chem. Soc. 2017, 139, 3774-3783.

(67) Heidary, N.; Ly, K. H.; Kornienko, N. Probing $\mathrm{CO}_{2}$ Conversion Chemistry on Nanostructured Surfaces with Operando Vibrational Spectroscopy. Nano Lett. 2019, 19, 4817-4826.

(68) Love, J. C.; Estroff, L. A.; Kriebel, J. K.; Nuzzo, R. G.; Whitesides, G. M. Self-Assembled Monolayers of Thiolates on Metals as a Form of Nanotechnology. Chem. Rev 2005, 105, 1103-1170.

(69) Kuhl, K. P.; Cave, E. R.; Abram, D. N.; Jaramillo, T. F. New Insights into the Electrochemical Reduction of Carbon Dioxide on Metallic Copper Surfaces. Energy Environ. Sci. 2012, 5, 7050-7059.

(70) Lobaccaro, P.; Singh, M. R.; Clark, E. L.; Kwon, Y.; Bell, A. T.; Ager, J. W. Effects of Temperature and Gas-Liquid Mass Transfer on the Operation of Small Electrochemical Cells for the Quantitative Evaluation of $\mathrm{CO}_{2}$ Reduction Electrocatalysts. Phys. Chem. Chem. Phys. 2016, 18, 26777-26785.

(71) Clark, E. L.; Resasco, J.; Landers, A.; Lin, J.; Chung, L.-T.; Walton, A.; Hahn, C.; Jaramillo, T. F.; Bell, A. T. Standards and Protocols for Data Acquisition and Reporting for Studies of the Electrochemical Reduction of Carbon Dioxide. ACS Catal. 2018, 8, $6560-6570$

(72) Wuttig, A.; Yoon, Y.; Ryu, J.; Surendranath, Y. Bicarbonate Is Not a General Acid in Au-Catalyzed $\mathrm{CO}_{2}$ Electroreduction. J. Am. Chem. Soc. 2017, 139, 17109-17113.

(73) Dunwell, M.; Luc, W.; Yan, Y.; Jiao, F.; Xu, B. Understanding Surface-Mediated Electrochemical Reactions: $\mathrm{CO}_{2}$ Reduction and Beyond. ACS Catal. 2018, 8121-8129.

(74) Zhang, B. A.; Ozel, T.; Elias, J. S.; Costentin, C.; Nocera, D. G. Interplay of Homogeneous Reactions, Mass Transport, and Kinetics in Determining Selectivity of the Reduction of $\mathrm{CO}_{2}$ on Gold Electrodes. ACS Cent. Sci. 2019, 5, 1097-1105.

(75) Biedermann, F.; Uzunova, V. D.; Scherman, O. A.; Nau, W. M.; De Simone, A. Release of High-Energy Water as an Essential Driving Force for the High-Affinity Binding of Cucurbit $[n]$ urils. J. Am. Chem. Soc. 2012, 134, 15318-15323.

(76) Azcarate, I.; Costentin, C.; Robert, M.; Savéant, J.-M. ThroughSpace Charge Interaction Substituent Effects in Molecular Catalysis 
Leading to the Design of the Most Efficient Catalyst of $\mathrm{CO}_{2}$-to-CO Electrochemical Conversion. J. Am. Chem. Soc. 2016, 138, 1663916644.

(77) Nichols, E. M.; Derrick, J. S.; Nistanaki, S. K.; Smith, P. T.; Chang, C. J. Positional Effects of Second-Sphere Amide Pendants on Electrochemical $\mathrm{CO}_{2}$ Reduction Catalyzed by Iron Porphyrins. Chem. Sci. 2018, 9, 2952-2960.

(78) Rosen, B. A.; Salehi-Khojin, A.; Thorson, M. R.; Zhu, W.; Whipple, D. T.; Kenis, P. J. A.; Masel, R. I. Ionic Liquid-Mediated Selective Conversion of $\mathrm{CO}_{2}$ to $\mathrm{CO}$ at Low Overpotentials. Science 2011, 334, 643-644.

(79) Lau, G. P. S.; Schreier, M.; Vasilyev, D.; Scopelliti, R.; Grätzel, M.; Dyson, P. J. New Insights Into the Role of Imidazolium-Based Promoters for the Electroreduction of $\mathrm{CO}_{2}$ on a Silver Electrode. J. Am. Chem. Soc. 2016, 138, 7820-7823.

(80) Hendon, C. H.; Rieth, A. J.; Korzyński, M. D.; Dincǎ, M. Grand Challenges and Future Opportunities for Metal-Organic Frameworks. ACS Cent. Sci. 2017, 3, 554-563.

(81) Hod, I.; Sampson, M. D.; Deria, P.; Kubiak, C. P.; Farha, O. K.; Hupp, J. T. Fe-Porphyrin-Based Metal-Organic Framework Films as High-Surface Concentration, Heterogeneous Catalysts for Electrochemical Reduction of $\mathrm{CO}_{2}$. ACS Catal. 2015, 5, 6302-6309.

(82) Diercks, C. S.; Lin, S.; Kornienko, N.; Kapustin, E. A.; Nichols, E. M.; Zhu, C.; Zhao, Y.; Chang, C. J.; Yaghi, O. M. Reticular Electronic Tuning of Porphyrin Active Sites in Covalent Organic Frameworks for Electrocatalytic Carbon Dioxide Reduction. J. Am. Chem. Soc. 2018, 140, 1116-1122.

(83) Ginovska-Pangovska, B.; Dutta, A.; Reback, M. L.; Linehan, J. C.; Shaw, W. J. Beyond the Active Site: The Impact of the Outer Coordination Sphere on Electrocatalysts for Hydrogen Production and Oxidation. Acc. Chem. Res. 2014, 47, 2621-2630.

(84) Caserta, G.; Roy, S.; Atta, M.; Artero, V.; Fontecave, M. Artificial Hydrogenases: Biohybrid and Supramolecular Systems for Catalytic Hydrogen Production or Uptake. Curr. Opin. Chem. Biol. 2015, 25, 36-47.

(85) Reuillard, B.; Warnan, J.; Leung, J. J.; Wakerley, D. W.; Reisner, E. A Poly(Cobaloxime)/Carbon Nanotube Electrode: Freestanding Buckypaper with Polymer-Enhanced $\mathrm{H}_{2}$-Evolution Performance. Angew. Chem., Int. Ed. 2016, 55, 3952-3957.

(86) Birdja, Y. Y.; Vos, R. E.; Wezendonk, T. A.; Jiang, L.; Kapteijn, F.; Koper, M. T. M. Effects of Substrate and Polymer Encapsulation on $\mathrm{CO}_{2}$ Electroreduction by Immobilized Indium(III) Protoporphyrin. ACS Catal. 2018, 8, 4420-4428.

(87) Lancaster, L.; Abdallah, W.; Banta, S.; Wheeldon, I. Engineering Enzyme Microenvironments for Enhanced Biocatalysis. Chem. Soc. Rev. 2018, 47, 5177-5186. 